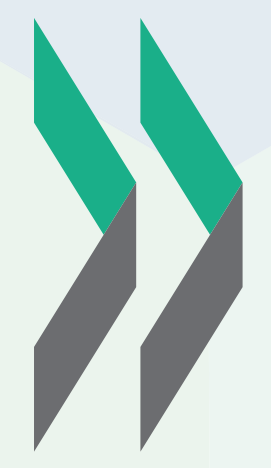

\title{
How is students' motivation related to their performance and anxiety?
}

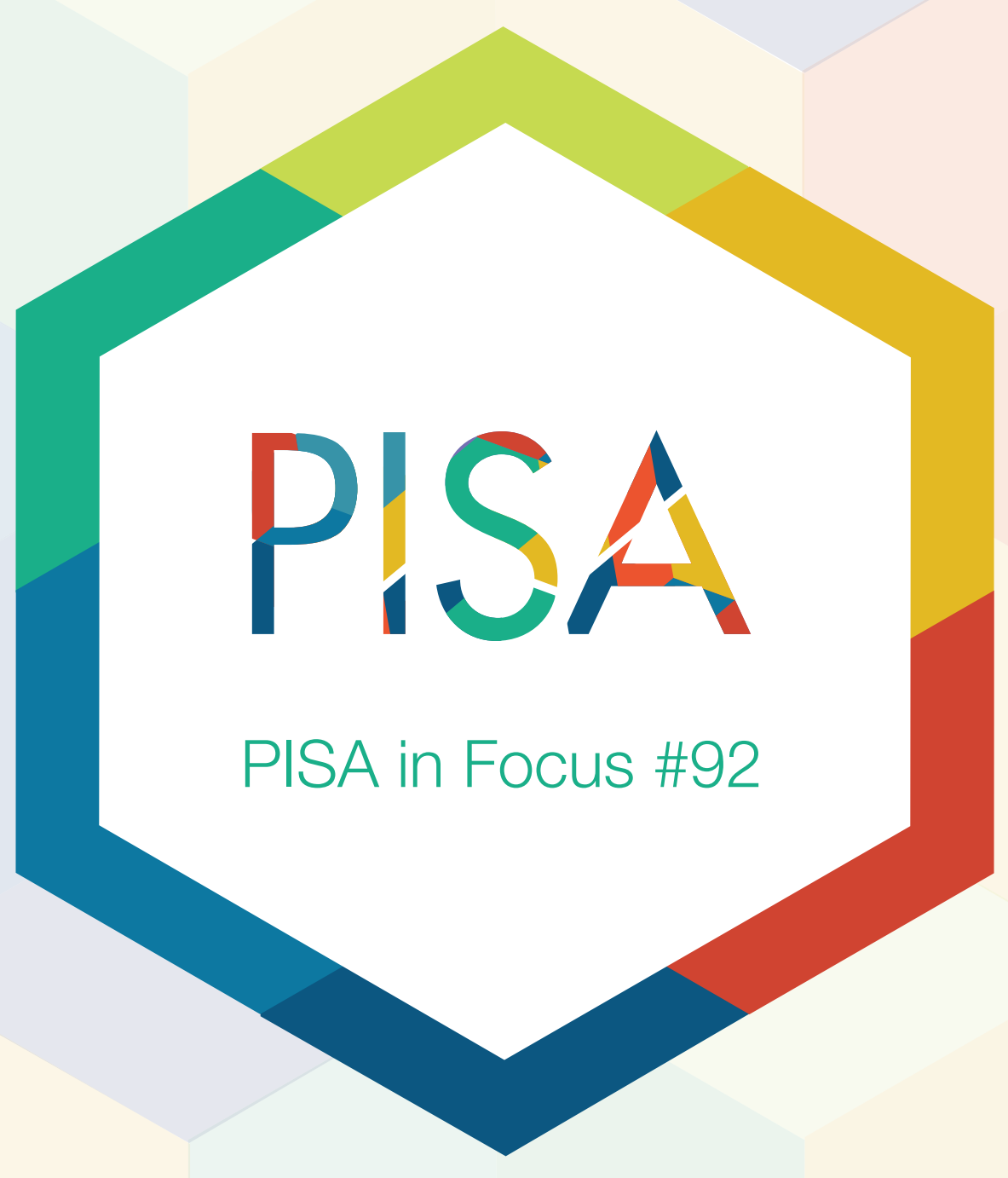




\section{How is students' motivation related to their performance and anxiety?}

- In almost all participating education systems, 15-year-old students who report greater motivation to achieve also perform better in the PISA assessment.

- Students in socio-economically advantaged environments perform better and show greater motivation than students in disadvantaged environments.

- Motivation, particularly when it is a response to external incentives, is associated with anxiety.

PISA has extensively measured student achievement for over 15 years. But cognitive performance is only one aspect of success at school; another is general well-being. The PISA 2015 questionnaire included a comprehensive section on student well-being designed to understand students' mental health, satisfaction with life, aspirations and socialisation. This PISA in Focus examines two of these aspects: motivation and anxiety.

Students in 55 education systems were asked about their motivation to achieve, both in school and in life. In particular, they reported the extent to which they agreed or disagreed with the following five statements:

- I want top grades in most or all of my courses.

- I want to be able to select from among the best opportunities available when I graduate.

- I want to be the best, whatever I do.

- I see myself as an ambitious person.

- I want to be one of the best students in my class.

Large differences in motivation were seen across countries. For example, less than $40 \%$ of students in Belgium, Finland, Japan, the Netherlands and Switzerland stated that they want to be the best, whatever they do, while over 90\% of students in Colombia, Israel, Thailand, the United Kingdom and the United States reported likewise. More than nine in ten 15-year-olds in Tunisia, but just over one in four 15-year-olds in the Dominican Republic, stated that they saw themselves as ambitious. These country differences may reflect more than just disparities in motivation; they also reflect, for example, differences between countries in how socially acceptable it is to acknowledge ambition and seek individual success, or differences between countries in what behaviours are considered to reflect high and low motivation.

Across countries, the percentage of students who agreed with the above statements is not strongly related to performance in the PISA 2015 assessment. Within almost every education system, however, motivation was positively associated with performance. In other words, students who reported greater motivation to do well also scored higher than other students in their country. This association was not statistically significant in only two countries: Belgium and Singapore.

For some, motivation may act as a self-fulfilling prophecy: students who aim higher end up going further. These students are often more willing to invest the effort required to perform well and achieve their goals. The positive results of this extra effort accumulate incrementally over the course of a student's education through, for example, better performance on assignments and tests. As a result, students gain greater self-confidence. This, in turn, can feed back into a virtuous cycle whereby students find it easier and more gratifying to devote themselves to attaining their goals, hence they are even more likely to succeed. Similarly, while low motivation may result in poor achievement, it may also be the consequence of low achievement if such poor performance generates frustration and a sense of helplessness. 


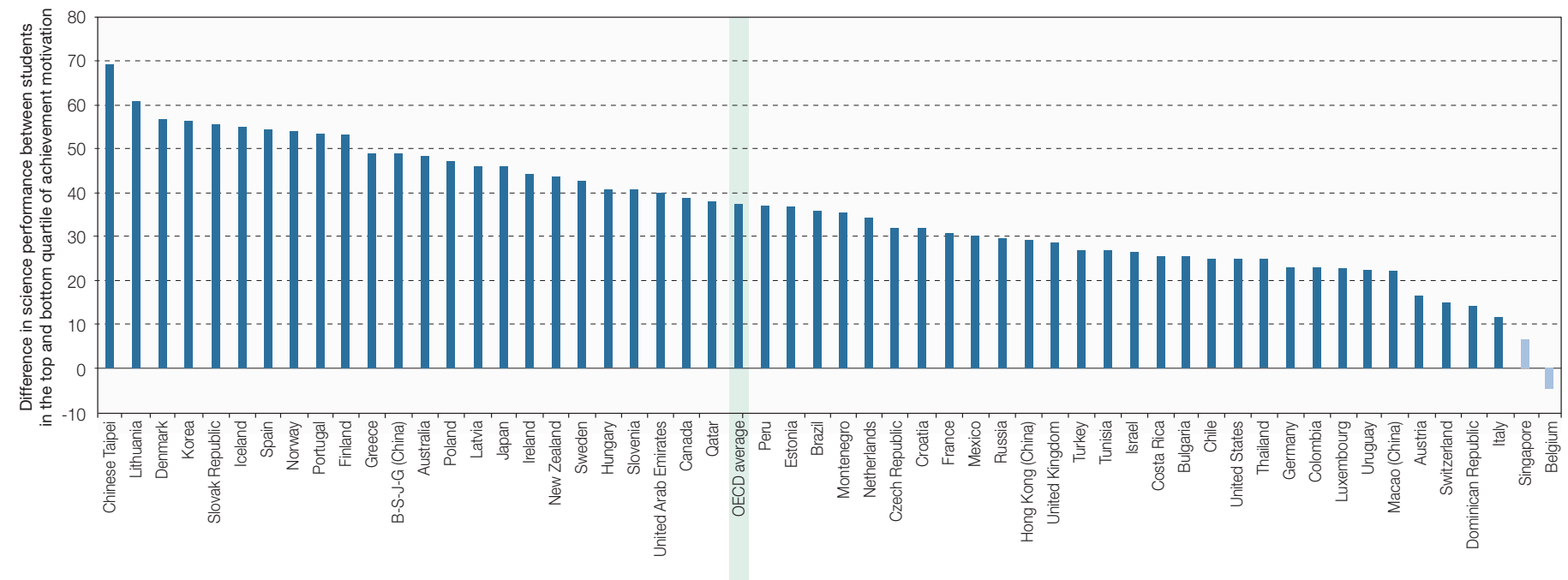

Notes: B-S-J-G (China) refers to Beijing-Shanghai-Jiangsu-Guangdong (China). Score differences that are statistically significant are shown in a darker tone.

Countries and economies are ranked in descending order of the difference in science performance between students in the top and bottom quarter of achievement motivation. Source: OECD, PISA 2015 Database, Table III.5.5a.

\section{Both motivation and performance are related to the socio-economic profile of schools.}

The link between motivation and performance can, to some extent, be attributed to disparities in students' and schools' socioeconomic profile. Advantaged students and students attending advantaged schools (regardless of their own family's socio-economic status) have consistently performed better than disadvantaged students and students attending disadvantaged schools across all cycles of PISA and across all subjects. At the same time, in almost all countries, advantaged students also report greater motivation to achieve than disadvantaged students. For instance, on average across OECD countries in 2015, advantaged students were 13 percentage points more likely to report that they see themselves as ambitious and 11 percentage points more likely to report that they want to be among the best students in their class.

Thus, students in advantaged environments show both stronger performance and greater motivation to achieve. This may be because the adults in these students' lives treat them differently: their parents and teachers believe and expect that they will succeed, and they provide them with the resources and enrichment opportunities that will help them attain their goals. These students also tend to be exposed to a variety of role models who work in high-skilled occupations after completing long, and often selective, education tracks. These students know that, in order to be able to select from among the best education and career opportunities available later on, they will have to study and do well in school. By contrast, students in disadvantaged environments may not even know what opportunities are available to them after graduation. With vaguer ideas about their goals, they may feel less motivated to work hard at school.

\section{Highly motivated students are more likely to suffer from anxiety.}

In addition to being associated with better performance, greater motivation is associated with higher anxiety. In Belgium, the Czech Republic, Germany, the Netherlands and Switzerland, where relatively few students (less than 45\%) reported that they want to be one of the best students in their class, relatively few students (also less than 45\%) reported that they feel very anxious before sitting a test even if they are well prepared for it. The opposite is true in Colombia, Costa Rica, the Dominican Republic and Singapore, where students are particularly likely both to be driven to succeed and to feel anxious before a test. 


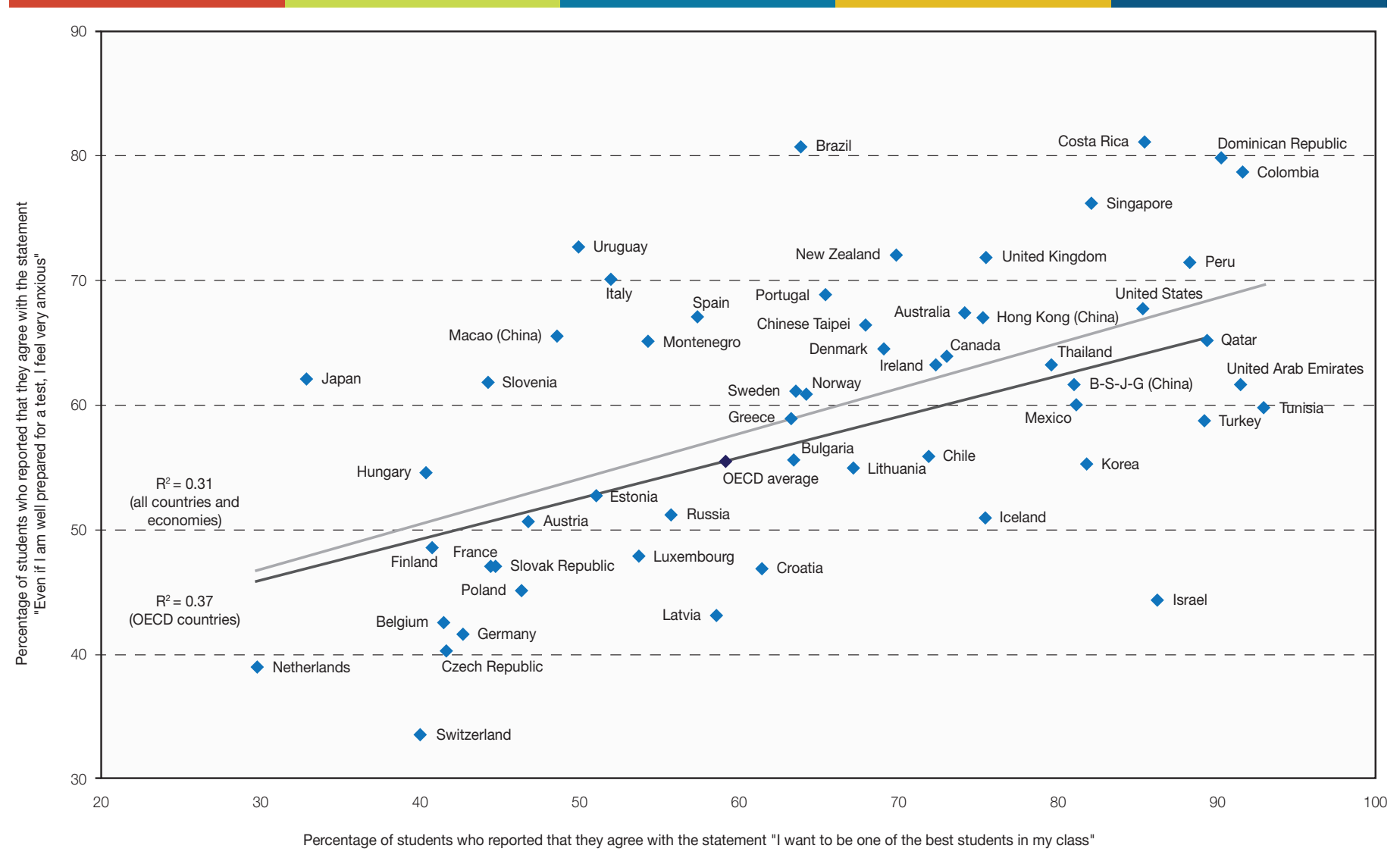

Note: B-S-J-G (China) refers to Beijing-Shanghai-Jiangsu-Guangdong (China)

Source: OECD, PISA 2015 Database, Tables III.4.1 and III.5.1.

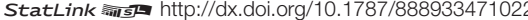

The relationship between motivation and anxiety is also observed within countries. Greater motivation to achieve is often related to higher levels of schoolwork-related anxiety. In all but three countries/economies (Germany, Hong Kong [China] and Iceland), students who reported that they want top grades in most or all of their courses were also more likely to report feeling very anxious even if they are well-prepared for a test. The relationship is particularly strong in Colombia, Costa Rica, the Dominican Republic, Korea, Portugal, Qatar, Chinese Taipei and Turkey.

The association between students' motivation and anxiety may depend on the nature of this motivation. Students who are extrinsically motivated want to do well because their parents, teachers and peers hold high expectations for them; students who are intrinsically motivated hold high expectations for themselves and want to realise those expectations for themselves, not for others. Students can hold both kinds of motivation simultaneously; indeed some students may internalise extrinsic motivation to the extent that they claim as their own the expectations that others have of them.

But external motivation can lead to stress and anxiety as students fear shame and censure from others if they fail. These students may develop perfectionist tendencies and eventually suffer from discouragement, a lack of confidence and burnout.

In fact, of the five statements that measure students' motivation in the PISA 2015 questionnaire, "I see myself as an ambitious person" is perhaps the least extrinsic because students are measuring themselves against themselves, not against others (in wanting to be "the best") or against others' expectations (in the form of "grades" or "opportunities"). Students who see themselves as ambitious were, on average across OECD countries, slightly less likely to feel anxious before sitting a test even if they were well prepared for it or to get very tense when they study. 


\section{The bottom line}

Motivation is clearly associated with performance: students who reach higher achieve more. However, the well-being of highly motivated students can suffer if that motivation is spurred only by comparing themselves with others or by others' expectations. Parents and teachers should reflect on the expectations they hold for students. Low expectations, especially for students in disadvantaged environments, may beget disengagement and a lack of effort; but while setting ambitious goals can help motivate students to work hard at school, students need to understand - and feel - that setbacks and failure are not a source of shame, but a valuable part of learning.

\section{For more information}

Contact: Jeffrey Mo (Jeffrey.MO@oecd.org)

See: OECD (2017), PISA 2015 Results (Volume III): Students' Well-Being, PISA, OECD Publishing, Paris, https://doi.org/10.1787/9789264273856-en.

Coming next month: Do countries with greater gender equality have smaller gender gaps in STEM participation? 
This paper is published under the responsibility of the Secretary-General of the OECD. The opinions expressed and the arguments employed herein do not necessarily reflect the official views of OECD member countries.

This document, as well as any data and map included herein, are without prejudice to the status of or sovereignty over any territory, to the delimitation of international frontiers and boundaries and to the name of any territory, city or area.

The statistical data for Israel are supplied by and under the responsibility of the relevant Israeli authorities. The use of such data by the OECD is without prejudice to the status of the Golan Heights, East Jerusalem and Israeli settlements in the West Bank under the terms of international law.

This work is available under the Creative Commons Attribution-NonCommercial-ShareAlike 3.0 IGO (CC BY-NC-SA 3.0 IGO). For specific information regarding the scope and terms of the licence as well as possible commercial use of this work or the use of PISA data please consult Terms and Conditions on www.oecd.org. 